\title{
QUALIDADE E PRODUTIVIDADE EM PESSEGUEIRO E ESTABELECIMENTO DO TREVO BRANCO COMO COBERTURA, INFLUENCIADOS PELA APLICAÇÃO DE BORO
}

\author{
QUALITY AND PRODUCTIVITY OF PEACH FRUITS \\ AND WHITE CLOVER ESTABLISHMENT AS COVERAGE, \\ INFLUENCED BY THE BORON APPLICATION
}

\author{
Luís Fernando ROVEDA ${ }^{1}$ \\ Renato Rezende Young BLOOD ${ }^{1}$ \\ Antonio Carlos Vargas MOTTA ${ }^{2}$ \\ Beatriz Monte SERRAT ${ }^{2}$
}

\begin{abstract}
RESUMO
Existe poucas informações sobre a necessidade do uso de B (boro) em pomares de pessegueiros (Prunus persica) no sul do Brasil. Assim, foi instalado um experimento em Campo do Tenente - PR, para avaliar o efeito da aplicação de B em um pomar comercial da cultivar Coral no quinto ano de produção, submetido ao sistema de produção integrada. Os tratamentos consistiam nas aplicações de $0,1,2$ e $4 \mathrm{~kg}$ de B.ha-1, aplicados no outono nas entrelinhas. Foram avaliados a produtividade, qualidade do fruto, teores foliares e crescimento de trevo nas entrelinhas. Foram coletadas mostras de solo em duas profundidades $(0-20$ e $20-40 \mathrm{~cm})$ e em três períodos ( 3,9 e 15 meses após a aplicação) para análises químicas. Incrementos lineares de 0,31, 0,09 e 0,01 mg B.dm ${ }^{-3}$ na profundidade de 0-20 cm e de 0,27, 0,12 e 0,02 mg B.dm ${ }^{-3}$ na profundidade de $20-40 \mathrm{~cm}$ foram observados após 3,9 e 15 meses, respectivamente. Estes incrementos resultaram em uma recuperação de 76, 28 e $5 \%$ de $B$ para os três períodos de amostragem. Produtividade e Brix ${ }^{\circ}$ não foram afetados pelos tratamentos. Aplicação de $4 \mathrm{~kg}$.ha-1 promoveu aumento na consistência de polpa. Nas análises foliares de macro e micronutrientes, não mostraram variações significativas. O trevo branco obteve aumento na percentagem de área, mas sem diferenças significativas. Assim, o Boro apresentou aumento na consistência de polpa e um baixo efeito residual no solo.
\end{abstract}

Palavras-chave: B no solo, produção integrada, B no pêssego, Trifolium repens.

\begin{abstract}
There is little information about necessity of Boron application for peach (Prunus persica) orchards at South of Brazil. So, an experiment was installed to evaluate the response to $B$ application at a five-year old commercial peach orchard, using Coral cultivar. The orchard was located at Campo do Tenente county, Parana state and managed under Integrated Production System. The treatments consisted of four B rates $\left(0,1,2\right.$ and $4 \mathrm{~kg}$ of B.ha- $\left.{ }^{-1}\right)$, applied during Fall on alley area. Yield, foliar analysis, and fruit quality (consistence, $\mathrm{Brix}^{\circ}$, caliber distribuition) for peach and growth for white clover (Trifolium repens) were obtained to evaluate the effect $\mathrm{B}$ application. To determine extractable $B$, soil samples were collected from two layers $(0-20$ and $20-40 \mathrm{~cm})$, during three period $(3,9$ and 15 months after

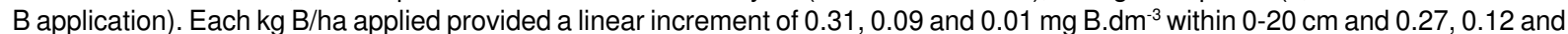
$0.02 \mathrm{mg} \mathrm{B} \mathrm{dm}^{-3}$ within $20-40 \mathrm{~cm}$ depth, after 3,6 and 9 months, respectively. These increments correspond 76,28 and $5 \%$ of $B$ recovering within $0-40 \mathrm{~cm}$ depth for three sampling periods. Beneficial effect of $B$ application was only observed for pulp consistency with higher value for the biggest $B$ rate. Boron application did not result in change on the foliar concentration of macro and micronutrients evaluated. The white clover obtained increase in the percentage of cover area but without significant differences. In conclusion, B application had a low residual effect in the soil and enhanced the pulp.

Key- words: $B$ in the soil, integrated production, $B$ in the peach, Trifolium repens.
\end{abstract}

\footnotetext{
${ }^{1}$ Acadêmico do curso de Eng. Agronômica da UFPR. Rua Luis Ronaldo Canalli 3025 CEP 81230250 Curitiba -Paraná- Brasil. Ifroveda@uol.com.br.

${ }^{2}$ Eng. Agr. Ms. Dr.- Prof. Do departamento de Solos e Eng. Agrícola do setor de Ciências Agrárias da UFPR.
} 


\section{INTRODUÇÃO}

Deficiência de Boro (B) nas plantas tem sido relatado em diferentes condições de solo e planta (JONES Jr, 1983). Levantamentos em solos paranaenses constataram que das 635 amostras analisadas apenas $15,54 \%$ mostram-se com níveis adequados deste elemento (LUCHESE et al., 1994), sugerindo a possibilidade de resposta a sua aplicação.

Todavia resultados do uso de B para as diferentes culturas tem sido inconsistente, variando de ausência de resposta (PETERSON e MACGREGOR, 1966; LOMAN Filho, 1999) no milho, (GERALDO, 2000) soja e (PAULETTI, 1999) trigo, o grande aumento na produtividade no repolho (BERGAMIN et al., 2005) e em leguminosas (SMITH et al., 1993). Contudo, alguns produtores têm utilizado este micronutriente em fruteiras de caroço, tendo como base recomendações de outras culturas como maçã (MOTTA et al., 2004), com intuito de aumentar o pegamento e formação de frutos e melhorando a sua qualidade (MALAVOLTA et al., 1997).

Desde a descoberta da essencialidade do Boro (B) para as plantas, este micronutriente tem-se mostrado benéfico na fase de florescimento, pois na época em que acontece a floração, a planta esta exposta a períodos de alta umidade e baixas temperaturas, podendo ocasionar uma queda na fertilização (RUSSEL, 1957). Diante de condições adversas como, por exemplo, queda de temperatura, a polinização não alcança seu melhor potencial, pois muitas vezes a flor se deteriora antes da fertilização acontecer. Neste momento o Boro auxilia e acelera o processo de formação do tubo polínico contribuindo com o aumento do número total de frutos por planta (HANSON, 1991).

Além da atuação na polinização, o Boro também pode afetar o crescimento de ramos, pois o mesmo atua no desenvolvimento completo das plantas como no seu crescimento meristemático, podendo a sua deficiência gerar um desenvolvimento precário das pontas de ramos, com conseqüências danosas às plantas que têm nos ramos do ano o seu potencial produtivo. Desempenha ainda, importante papel na migração de carboidratos e no metabolismo dos mesmos (MARSCHNER, 1986).

Nos pomares sob o sistema de produção integrada, é preconizada a inclusão de cobertura viva nas entre linhas, principalmente leguminosas, a fim de proteger o solo e fornecer $\mathrm{N}$ para cultura principal além de propiciar uma competição com as plantas invasoras (ESPINDOLA et al., 1997). O Trevo Branco (Trifolium repens) possui grande habilidade para competir com gramíneas perenes, e apresenta uma alta capacidade de fixação de nitrogênio, podendo chegar a valores de até $200 \mathrm{Kg} \cdot \mathrm{ha}^{-1}$. ano-1, o que a torna de grande potencial como cobertura viva (COMISSÃO PARANAENSE de AVALIAÇÃO de FORRAGEIRAS, 1996). Com base nestas informações, a adubação química de nitrogênio poderá ser reduzida significativamente, diminuindo os custos para o produtor, além de reduzir sensivelmente a poluição causada pelo nitrato no lençol freático, através da liberação gradativa deste nutriente. Todavia, a implantação e estabelecimento de leguminosas podem não ocorrer de maneira adequada caso as condições de solo não sejam favoráveis, tais como baixo $\mathrm{pH}$, carências de $\mathrm{P}$ e B no solo (SMITH et al., 1993).

Sendo, a calagem e a adubação fosfatada de maneira geral práticas comuns em solos cultivados sob fruticultura. Ao contrario a adubação com Boro não vem sendo utilizado pela grande maioria dos produtores, sendo esse um dos fatores limitantes ao estabelecimento e a longevidade de leguminosas (HABY et al., 1993), por atuar no número, tamanho e viabilidade das sementes, deste modo interferindo na propagação natural da espécie. Ainda, por ser um elemento de alta mobilidade no perfil do solo e atuar no crescimento radicular, especialmente em condições de elevada acidez, o uso de B tem propiciado melhorias do desenvolvimento radicular de leguminosas em subsolos ácidos (SMITH et al., 1993; LENOBLE et al., 1996, FAVARETTO, 1999), contribuindo para absorção de água e nutrientes.

O objetivo do presente trabalho foi verificar o efeito da aplicação do Boro na cultura do pessegueiro e o desenvolvimento do trevo branco utilizado como cobertura viva nas entrelinhas.

\section{MATERIAIS E MÉTODOS}

Implantação do experimento: Experimento foi instalado em 2004 no Município de Campo do Tenente, clima Cfb (Subtropical sempre úmido, com chuvas bem distribuídas, verões brandos), localizado no Primeiro Planalto a uma altitude de $907 \mathrm{~m}$, em um pomar comercia de pessegueiro (Prunus persica) na propriedade do Sr. Mario Kaiss, localizado a $90 \mathrm{~km}$ de Curitiba-PR. Plantas da variedade Coral foram plantadas em um espaçamento $6 \times 4 \mathrm{~m}$, no ano de 1996.

O solo presente na região é associação Cambissolos Háplicos + Argissolo vermelho-amarelos (EMBRAPA, 1999). Curitiba O clima da região é subtropical, com médias térmicas anuais de $17^{\circ} \mathrm{C}$ e chuvas pouco abundantes $(1.077 \mathrm{~mm}$ anuais, em média), regularmente distribuídas.

O experimento foi instalado em blocos ao acaso com quatro repetições, em uma área de 0,57 ha, totalizando 240 plantas, cada parcela possuía aproximadamente 0,035 ha e era constituída por 15 plantas, distribuídas igualmente em três linhas, sendo avaliadas as três plantas do centro das parcelas.

Os tratamentos utilizados foram nas doses de 0 (testemunha), 1, 2 e $4 \mathrm{~kg} \cdot \mathrm{ha}^{-1}$ de B, na forma de ácido bórico. Para a distribuição mais homogênea do $\mathrm{B}$ na área, o ácido bórico foi misturado com areia obtendo-se assim um volume maior, aplicando-se manualmente a lanço nas entrelinhas das parcelas selecionadas, realizada no dia 29 de abril de 2004 .

A semeadura do trevo branco ( Trifolium repens L.), foi realizada após as aplicações dos tratamentos utilizando-se o equivalente a $3 \mathrm{~kg} \cdot \mathrm{ha}^{-1}$ de sementes, 
previamente peletizadas com calcário e inoculadas com a bactéria específica do gênero Rhizobium.

Foram coletadas amostras de solo aos 3, 9 e 15 meses após adubação com $B$, em duas profundidades $(0-20$ e $20-40 \mathrm{~cm})$, sendo que em cada parcela foram coletadas 6 sub amostras para formar uma amostra composta. As análises químicas do solo para fins de fertilidade foram realizadas nos laboratórios da UFPR, segundo Marques e Motta (2003) conforme exposto na Tabela 1. Para a $1^{\circ}$ amostragem realizou-se análise de rotina em conjunto com a de Boro, para caracterização do solo, sendo que para as outras duas amostragens, somente analisou-se o teor de Boro no solo. Os resultados das análises de solo foram interpretados e prescritos segundo Raij et al. (1996).

TABELA 1 - Médias das análises químicas de rotina, realizadas com amostras de solo nas profundidades (0-20, 20-40) coletadas sob a cultura de pessegueiro da cultivar Coral, no município de Campo Tenente-PR.

\begin{tabular}{|c|c|c|c|c|c|c|c|c|c|c|c|}
\hline \multirow[t]{2}{*}{$\begin{array}{l}\text { Prof. } \\
(\mathrm{cm})\end{array}$} & \multicolumn{2}{|c|}{$\mathrm{pH}$} & $\mathrm{Al}^{+3}$ & $\mathrm{H}^{+}+\mathrm{Al}^{+3}$ & $\mathrm{Ca}^{+2}$ & $\mathrm{Mg}^{+2}$ & $\mathrm{~K}^{+}$ & $\mathrm{T}$ & \multirow{2}{*}{$\begin{array}{c}\mathrm{P} \\
\mathrm{mg} / \mathrm{dm}^{3}\end{array}$} & \multirow{2}{*}{$\frac{\mathrm{C}}{\mathrm{g} / \mathrm{dm}^{3}}$} & \multirow{2}{*}{$\begin{array}{l}\mathrm{V} \\
\%\end{array}$} \\
\hline & $\mathrm{CaCl}_{2}$ & SMP & \multicolumn{6}{|c|}{$\mathrm{cmol}_{\mathrm{d}} / \mathrm{dm}^{3}$} & & & \\
\hline $0-20$ & 4,93 & 5,88 & 0,15 & 5,53 & 3,04 & 2,16 & 0,29 & 11,01 & 3,88 & 23,55 & 49,80 \\
\hline $20-40$ & 4,43 & 5,35 & 1,38 & 8,23 & 1,93 & 1,17 & 0,19 & 11,51 & 3,30 & 21,58 & 29,17 \\
\hline
\end{tabular}

Metodologia para determinação do $B$ e recuperação pelo extrator: Análises do $\mathrm{B}$ no solo foram realizadas pela extração com cloreto de bário aquecido em forno de microonda e determinado por colorimetria utilizando azometina- $\mathrm{H}$, segundo metodologia descrita por Silva (1999). Com base nos coeficientes lineares de acréscimo de Boro no solo, obtidos pela regressão, calculou-se a recuperação de $B$ pelo extrator químico utilizado para ambas as camadas (0-20 e 20-40). A recuperação total de Boro foi obtida pela soma das duas camadas.

Avaliação do Pessegueiro e Trevo: Foram realizadas análises quantitativas (número de frutos por planta, produtividade e calibre de frutos) e qualitativas (Grau Brix e Consistência de polpa), em respostas às respectivas doses de $\mathrm{B}$, assim como $\mathrm{a}$ avaliação da cobertura do Trevo Branco (Trifoliun repens).

A análises quantitativas basearam-se na contagem total do número de frutos por planta útil, realizada em outubro de 2004 , evitando o acúmulo das atividades no período da colheita. Em novembro de 2004 foram coletados 30 frutos por parcela. Com base no total de frutos por planta e peso médio dos frutos por parcela, foi calculada a produtividade em kg. planta ${ }^{-1}$, com base em 416 plantas. ha ${ }^{-1}$. Verificouse também o calibre desses frutos, classificando-os por tamanho, de acordo com o maior diâmetro transversal do fruto, para as seguintes classes de calibre: $0=$ frutos de diâmetro entre $\geq 2,5 \mathrm{a}<3,5 \mathrm{~cm}$; $1=$ frutos $\geq 3,5 \mathrm{a}<4,5 ; 2=\geq 4,5 \mathrm{a}<5,1 ; 3=\geq 5,1 \mathrm{a}$ $<5,6 ; 4=\geq 5,6$ a $<6,1 ; 5=\geq 6,1$ a $<6,76=\geq 6,7$ a $<7,3 ; 7=\geq 7,3$ a $<8 ; 8=\geq$ a 8 .

As análises qualitativas basearam-se na determinação da consistência de polpa em conjunto com a determinação do grau Brix. A consistência de polpa foi determinada através do penetrômetro com ponteira de $8 \mathrm{~mm}$. Foram selecionados 5 frutos por parcela, sendo que estes se apresentavam em ponto de colheita. Para esta análise retirou-se a casca das duas faces opostas da região equatorial da fruta, posicionando-se a ponteira perpendicularmente a polpa, para a posterior utilização do aparelho, obtendose a leitura em libras.

A determinação do grau Brix foi realizada com os mesmos 5 frutos. Estes foram descascados, cortados e colocados em centrífuga para obtenção do suco. Deste retirou-se uma gota para posterior leitura no refratômetro, obtendo-se também por leitura direta o grau Brix.

Para a avaliação do desenvolvimento do trevo branco avaliou-se porcentagem da cobertura no solo, por meio de notas de 0 a 5 , pré-estabelecidas visualmente. Para esta determinação, dentro de um espaço de uma armação de ferro em forma de quadrado $(0,5 \mathrm{~m} \times 0,5 \mathrm{~m})$, gerou-se as notas. A área com a maior quantidade de plantas recebeu nota 5 e aquela com a menor quantidade recebeu nota 0 . Para a calibração foi usada uma régua de um metro de comprimento sendo que no centro de cada $10 \mathrm{~cm}$ era feito um orifício. A régua foi jogada aleatoriamente 5 vezes em cada área e determinada as cinco diferentes notas. Com a régua no chão foi introduzido um arame em cada um dos dez orifícios e toda vez em que o arame tocava uma folha ou ramo de trevo era atribuído $10 \%$, obtendo-se valores em \% de área coberta para cada nota respectivamente. Após a calibração das notas, este mesmo quadrado foi lançado por 30 vezes dentro de cada parcela, atribuindo-se uma nota de modo que a porcentagem de cobertura das parcelas, determinando-se médias. Foram realizadas duas avaliações, a primeira em janeiro de 2005 e a segunda em julho de 2005.

Análise foliar: Foram coletadas amostras foliares de pêssego por parcela, sendo coletadas no verão e as folhas recém-amadurecidas do crescimento do ano, segundo método descrito por Malavolta 
ROVEDA, L.F. et al. Qualidade e produtividade em...

(1997), e analisadas em laboratório segundo Silva (1999).

Análise Estatística: Os dados foram avaliados pela analise de variância, e teste de média por Tukey a $5 \%$ de probabilidade de erro (SILVA, 2002). Procedeu-se também teste de regressão linear entre os teores de Boro no solo e entre as doses aplicadas.

\section{RESULTADOS E DISCUSSÃO}

Teores e recuperação de $B$ no solo, em função do tempo e profundidade do solo: Em geral os menores teores de $B$ obtidos foram próximos de $0,20 \mathrm{mg} \cdot \mathrm{kg}^{-1}$ na ausência de $B$, em ambas as camadas avaliadas, 0-20 e 20-40 cm de profundidade, valor considerado baixos $(0-0,20)$ por Raij et al. (1996). Além disso, diferente de outros elementos como, por exemplo, $\mathrm{P}$, $\mathrm{Cu}$ e $\mathrm{Zn}$ que em solos não revolvidos acumulam-se na superfície, decrescendo acentuadamente em profundidade, o B extraível não apresentou gradiente entre as camadas (Figura 1 e 2). Similar aos resultados obtidos por Mitchell et al. (1992), trabalhando com pastagem, e por Mahler et al. (1985), com sistemas de cultivo para grãos, os quais constataram pequenas variações de $B$ até profundidade próxima a $50 \mathrm{~cm}$, dada à alta mobilidade deste nutriente. Tal fato salienta a importância da amostragem em profundidade superior a $20 \mathrm{~cm}$, visto que tal camada pode ter participação importante no suprimento deste elemento às culturas.

A elevação da dose de B aplicado foi acompanhada de aumento linear da concentração de B extraível tanto nas camadas de 0-20 e $20-40 \mathrm{~cm}$ de profundidade, já na primeira avaliação, mostra uma pequena diferença entre a primeira e segunda camada em um curto espaço de tempo após a adubação (Figura 2), tal fato confirma a alta mobilidade do B no solo, dado pela baixa capacidade de adsorção do solo, por apresentar-se na forma aniônica ou como $\mathrm{H}_{3} \mathrm{BO}_{3}$ e não ser adsorvido especificamente pelas camadas do solo (PAVAN et al., 1988).
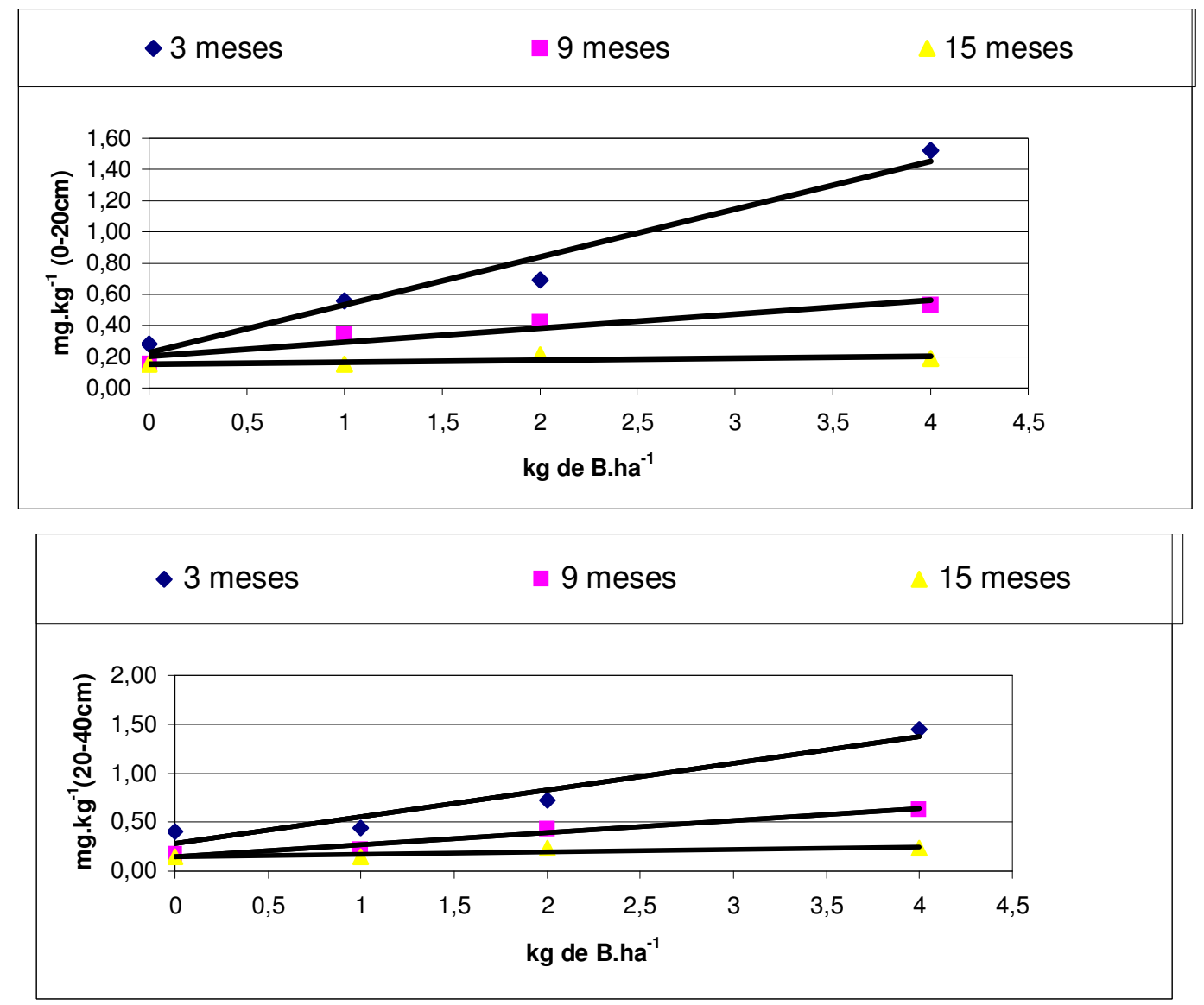

FIGURA 1 E 2 - Teores de B no solo, nas profundidades de 0-20 e 20-40 cm, respectivamente após 3, 9 e 15 meses de aplicação de doses crescentes de Boro, em amostras coletadas no município de Campo do Tenente-PR. 
Os maiores acréscimos foram observados após três meses da aplicação nas camadas de 0-20 (B no solo $\mathrm{mg} \cdot \mathrm{Kg}^{-1}=0,30 \cdot \mathrm{B}$ aplicado $+0,15, \mathrm{R}^{2}=$ $0,96^{\star \star}$ ) e de $20-40 \mathrm{~cm}$ (Boro no solo $\mathrm{mg} \cdot \mathrm{Kg}^{-1}=0,27 \cdot \mathrm{B}$ aplicado $\left.+0,27, R^{2}=0,93^{* \star}\right)$, respectivamente. Estes acréscimos também foram observados por Bergamin et al. (2005), com uso isolado ou em conjunto com adubo orgânico.

Após 9 meses esse acréscimo linear com a dose de $B$ foi mantido, mas com uma redução do incremento do nutriente para ambas as camadas avaliadas 0-20 (B no solo $\mathrm{mg} \cdot \mathrm{Kg}^{-1}=0,08 . \mathrm{B}$ aplicado+ $0,20, R^{2}=0,90^{\star \star}$ ) e $20-40$ ( $B$ no solo $\mathrm{mg} \cdot \mathrm{Kg}^{-1}=0,12 \cdot \mathrm{B}$ aplicado+ $\left.0,15, R^{2}=0,96^{* *}\right)$, passando a camada inferior a apresentar maiores coeficientes angulares. Maiores acréscimos com uso de Boro na camada de $20-40 \mathrm{~cm}$ (B no solo $\mathrm{mg} \cdot \mathrm{Kg}^{-1}=0,2$. B aplicado+ $\left.0,15, R^{2}=0,71 \mathrm{~ns}\right)$ permaneceu na terceira amostragem, bem como na camada de $0-20 \mathrm{~cm}$ (B no solo mg. $\mathrm{Kg}^{-1}=0,02 \cdot \mathrm{B}$ aplicado $+0,15, \mathrm{R}^{2}=0,71$ ns) após 15 meses, indicando que quantidade considerável de $\mathrm{B}$ já havia sido lixiviado. Os resultados obtidos confirmam o baixo efeito residual da adubação com B quando aplicado (GUPTA et al, 1967), o que confirma a necessidade de adubações freqüentes deste micronutriente segundo Adams et al (1994) e Comissão de Fertilidade Do Solo - RS/SC (1995).

Um elevado percentual do teor de $B$ foi obtido na primeira coleta, 3 meses após o solo ser tratado com este micronutriente (Figura 3). Cabe ressaltar que para as duas profundidades esse incremento de B foi de $76 \%$ correspondente ao volume de solo abaixo da área adubada (entrelinha). Contudo, aos 9 e 15 meses após a aplicação tais valores diminuíram para $28 \%$ e $5 \%$ respectivamente. Corroborando com os resultados obtidos por Gupta (1967) que constatou, após três meses, $81 \%$ de recuperação média para dois solos incubados com doses de Boro, sob diferentes condições de umidade, já sob condições de campo Gupta e Cutcliffe (1978) encontraram entre 35 e $62 \%$ de recuperação de Boro, aplicado em área total após a colheita de couves-nabo (Brassica-napus), sugerindo uma rápida perda por lixiviação.

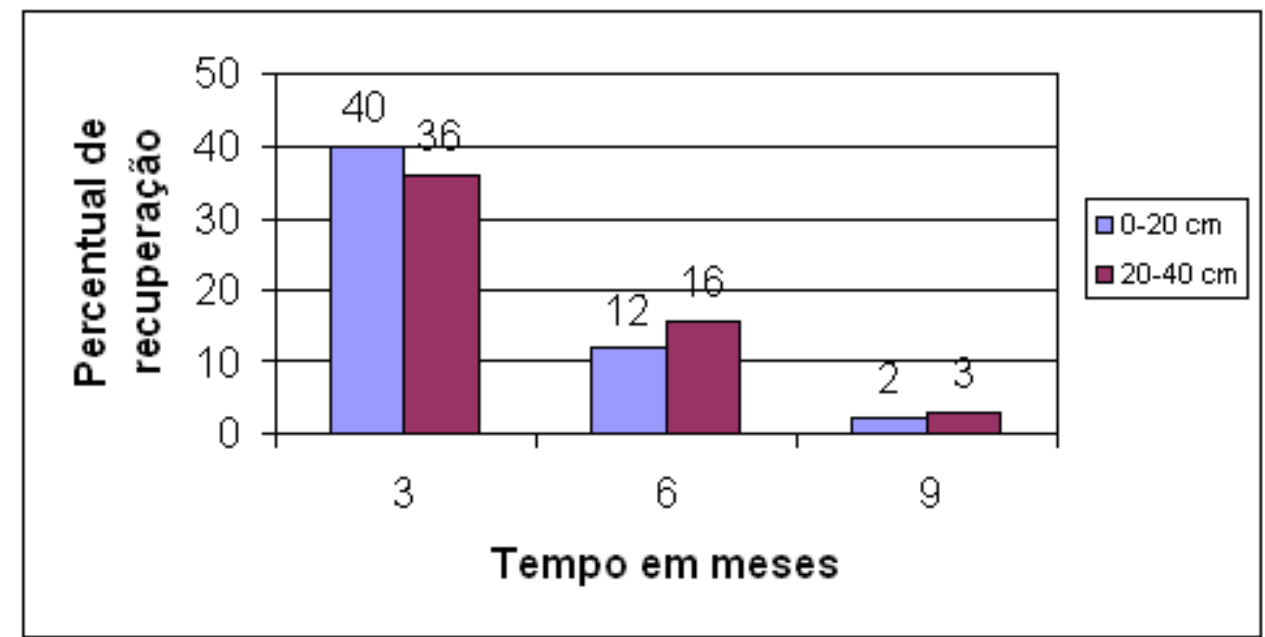

FIGURA 3 - Percentual de recuperação pelo extrator, considerando a média das doses aplicadas e $11^{\circ}, 2^{\circ}, \mathrm{e} 3^{\circ}$ coleta de amostras de solo em pomar de pêssego no município de Campo do Tenente - PR.

Efeito do uso do $B$ na produtividade do pêssego e estabelecimento do trevo.

Os resultados mostrados na Tabela 2 indicam

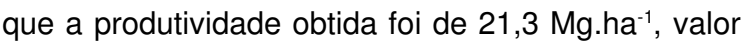
superior à média estadual $\left(7,4 \mathrm{Mg}^{-h^{-1}}\right)$ e a obtida no mesmo pomar no ano anterior (9 $\mathrm{Mg}^{-\mathrm{ha}^{-1}}{ }^{\text {), }}$ provavelmente como resposta ao incremento no uso de fertilizantes e melhoria nos tratos culturais. Tais valores são próximos aos observados para produção de pêssego obtida em outras áreas da região (PIFPR-CNPq, 2004). Todavia, não houve diferenças significativas das produtividades em relação às doses de B aplicadas. Os resultados sugerem que embora tenha sido aplicado o dobro, na mais alta dose, do que vem sendo recomendado para as culturas em geral, não se constatou efeito tóxico nas plantas indicando que a faixa entre deficiência e toxidez não seja muito estreita para essa cultura (LUCHESE et al., 1994).

Quanto ao trevo observou-se acréscimo na porcentagem de área coberta, porém não mostrou valores estatisticamente significativos (Tabela 2), diferentes dos encontrados por outros autores. Marschner (1986) sugere que as leguminosas como trevo sejam mais sensíveis e exigentes em $B$. Melhorias no estabelecimento e crescimento de leguminosas com a adição de B tem sido observadas também em solos ácidos sob diferentes condições (HABY et al., 1993; SMITH et al., 1993), principalmente pelo maior crescimento das raízes em profundidade 
(LeNoble et al, 1996 [19]; Favaretto et al., 1999 [11]). do pêssego.

Efeito da aplicação do B na qualidade do fruto

O efeito do uso do B na consistência de polpa é mostrado na Tabela 2, obtendo-se o melhor valor com a aplicação de 4 kg.ha ${ }^{-1}$ de $\mathrm{B}$, o qual diferiu estatisticamente das demais doses. O valor de 11,53 Ib foi o único que se enquadrou como normal dentro dos padrões para o cultivar (ARGENTA et al, 2004). Este resultado pode estar relacionado pelo fato de o Boro participar do funcionamento das membranas celulares. Em caso de deficiência, diminui a atividade da ATPase, caindo a disponibilidade de energia cai também a absorção iônica e para a passagem de açúcares e aminoácidos. A deficiência do B desencadeia várias alterações que vão do metabolismo dos açúcares propriamente dito até a membrana celular (MALAVOLTA et al., 1997; BLEVINS et al., 1998).

A maior consistência de fruto é desejável, pois propicia maior capacidade de manuseio sem causar danos, aumentando sua vida de prateleira.

TABELA 2 - Produtividades, consistência de polpa, Grau Brix e desenvolvimento do trevo (Trifolium repens). Médias dos dois períodos avaliados, em função de diferentes doses de B aplicadas em pomar de pêssego localizado no município de Campo de Tenente-PR.

Médias seguidas de mesma letra, na coluna, não diferem significativamente pelo teste de Tukey ao nível de $5 \%$ de probabilidade.

Além destas análises, foram ainda avaliados o peso e calibre de frutos (Tabela 3), os quais não apresentaram diferença significativa entre os tratamentos realizados na área.

TABELA 3 - Quantificação do tamanho e da massa dos frutos, valores referentes às médias dos tratamentos. Amostras coletadas sob a cultura de pessegueiro da cultivar Coral, no município de Campo Tenente-PR.

\begin{tabular}{ccc}
\hline CALIBRES & \% DO TOTAL & PESO MÉDIO $(\mathrm{g})$ \\
\hline III & 5,0 & 63,1 \\
IV & 47,5 & 88,3 \\
V & 36,0 & 106,2 \\
VI & 11,9 & 136,3 \\
VII & 1,0 & 186,0 \\
\hline
\end{tabular}

Concentração foliar de nutrientes: A aplicação de $B$ em diferentes doses não propiciou modificação nos teores foliares dos demais elementos avaliados. Os teores de macronutrientes $\mathrm{N}(26-35), \mathrm{P}(2-3), \mathrm{Mg}$ (3-5) e micronutrientes $\mathrm{Mn}(100-150), \mathrm{Zn}(30-40)$ observados (Tabela 4) encontram-se dentro da faixa considerada satisfatória (MALAVOLTA et al., 1997). Como o solo recebeu adubação nitrogenada uniforme, não foi possível observar alguma contribuição de $\mathrm{N}$ para o pêssego com o maior crescimento do trevo.

TABELA 4 - Resultados das análises químicas foliares, realizadas com amostras de plantas coletadas na cultura do pêssego, cultivar coral, no município de Campo do Tenente- PR.

\begin{tabular}{|c|c|c|c|c|c|c|c|c|c|c|}
\hline B & $\mathrm{N}$ & $\mathrm{P}$ & $\mathrm{K}$ & $\mathrm{Ca}$ & $\mathrm{Mg}$ & $\mathrm{Fe}$ & $\mathrm{Mn}$ & $\mathrm{Zn}$ & $\mathrm{Cu}$ & $B$ \\
\hline $\mathrm{Kg} \mathrm{ha}^{-1}$ & \multicolumn{10}{|c|}{ 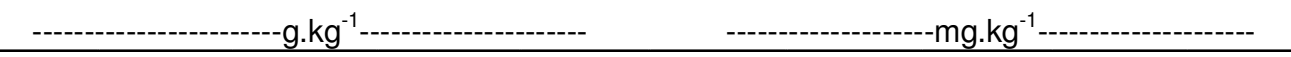 } \\
\hline 0 & 38 & 3,1 & 26,3 & 14,8 & 5,7 & 71 & 68 & 26 & 6 & 30,3 \\
\hline 1 & 39 & 2,9 & 25,4 & 14,3 & 5,4 & 67 & 65 & 27 & 6,8 & 30,0 \\
\hline 2 & 37 & 2,8 & 26,7 & 15,5 & 5,4 & 68 & 70 & 28 & 8 & 31,8 \\
\hline 4 & 39 & 3,1 & 26,1 & 13,9 & 5,3 & 68 & 56 & 24 & 6,3 & 32,5 \\
\hline
\end{tabular}


Todavia para a mesma referência os teores de $\mathrm{K}$ apresentaram-se um pouco acima e os de $\mathrm{Mn}$, Ca e Fe encontravam-se abaixo do normal, bem como o $\mathrm{Mn}$. Resultados similares têm sido relatados em pomares da região sem efeito sobre o potencial produtivo do pessegueiro (PIF-PR-CNPq, 2004 e DOLINSKI et al., 2005 ).

O nível de $\mathrm{B}$ foliar aumentou de modo linear ao seu uso (B mg.kg-1 $=30+0,64 \mathrm{~kg} \cdot \mathrm{ha}^{-1} B, R^{2}=$ 0,84 ), mas os acréscimos observados foram pouco expressivos, com um aumento de $0,64 \mathrm{mg} \cdot \mathrm{kg}^{-1}$ de B foliar para cada $\mathrm{kg}$ de $\mathrm{B}$ aplicado via solo.

O efeito do uso de B aplicado ao solo sobre o teor foliar tem sido variável. De um lado, não obtendo acréscimos para a cultura do milho e soja constatado por Loman Filho (2004) e Giroldo (2000) dentro das doses recomendadas para as culturas, e com pequeno acréscimo de $B$ foliar na cultura de algodão pela adição de $B$ no solo, a campo, aplicado em área total ou em sulco por Carvalho et al, (1996). Por outro lado às culturas de Brócolos e Repolho apresentaram grandes incrementos foliares de 3,7 e $5,5 \mathrm{mg} \cdot \mathrm{kg}^{-1}$ para cada $\mathrm{kg}$ de Boro aplicado, respectivamente (PIZETA et al., 2005). Da mesma forma teor foliar de B em Eucalyptus camaldulensis aumentou $36,5 \mathrm{mg} \cdot \mathrm{kg}^{-1}$ para cada kg.ha ${ }^{-1}$ de B aplicado (PINHEIRO, 1999).

A forma de aplicação do adubo ao solo pode ter um papel importante, como demonstraram Peterson e MacGregor (1966) que constataram menores aumentos de B na planta de milho quando incorporado na área total que no sulco, indicando maior eficiência para a aplicação em área total.

Assim como os teores no solo, grandes decréscimos no teor foliar de culturas de forrageiras com cortes sucessivos foram observados por (GUPTA, 1984), indicando que o tempo decorrido entre aplicação e amostragem do tecido foliar tem grande relevância e pode ter afetado os resultados aqui obtidos visto que decorreram aproximadamente 9 meses entre aplicação e coleta de amostra de folha.

Logo, o efeito da adubação com B sobre o seu teor foliar apresenta grande diferença entre as culturas, e as condições de solo e clima, havendo necessidade de mais trabalhos na avaliação das possíveis causa do pequeno aumento no teor foliar.

\section{CONCLUSÃO}

1 - Para o pessegueiro foi observado um leve aumento sobre o teor foliar de Boro, e efeito sobre a qualidade do fruto através do aumento da consistência de polpa, o que pode ter grande importância na resistência ao transporte e armazenamento.

2 - O Boro proporcionou aumento na porcentagem da área coberta do trevo, mas sem diferenças significativas.

3 - A concentração de Boro no solo apresentou aumento linear com a dose de Boro aplicada, principalmente após três meses da adubação, tanto na camada superficial quanto em profundidade o que indica uma rápida perda do elemento por lixiviação.

\section{REFERÊNCIAS}

1. ADAMS, J. F.: MITCHELL, C. C.: BRYANT, H.H. Soil test fertilizer recommendations for Alabama crops. Agronomy and Soils Dept. Series No. 178. Alabama Agricultural experiment Station, Alburn, AL. 1994.

2. ARGENTA, L. C.; FLORES-CANTILLANO F; BECKER W.F. Tecnologia pós-colheita para fruteira de caroço. In: MONTEIRO L. B.; MAY DE MIO L.L. FERRAZ B. M. MOTTAA. C. V. CUQUEL F. L. Fruteira de Caroço uma Visão Ecológica. Curitiba, 2004. p. 333-362.

3. BERGAMIN, L. G.; CRUZ, M. C. P. DA; FERREIRA, M. E.; BARBOSA, J. C. Produção de repolho em função da aplicação de boro associada a adubo orgânico. Horticultura Brasileira 23 (2): 311-315, 2005.

4. BLEVINS, D. G.; LUKASZEWSKI, K. M. Boron in plant structure and function. Annu. Rev. Plant Physiol. Plant Mol. Biol. Missouri, V. 49: pg 481-500: 1998.

5. CARVALHO, L. H.: SILVA, N. M.: BRASIL SOBRINHO, M. C.: KONDO, J. I. \& CHIAVEGATO, E. J. Aplicação de boro no algodoeiro, em cobertura e em pulverização foliar. R. Brasil Cia. Solo, Campinas, 20:265-269, 1996.

6. COMISSÃO DE FERTILIDADE DE SOLO-RS/SC. Recomendações de Adubação e de Calagem para os Estados do Rio Grande do Sul e de Santa Catarina. $3^{\circ}$ ed. Passo Fundo, 1995. p. 174-176.

7. COMISSÃ PARANAENSE DE AVALIAÇÃO DE FORRAGEIRAS. (Londrina PR) C733f Forragicultura no Paraná. Alda Lúcia Monteiro. Londrina, 1996. $305 \mathrm{pg}$.

8. DOLINSKI, M. A., SERRAT, B. M.; MOTTA, A. C.V.; CUQUEL, F.L. SOUZA, S. R. DE ; MIO, L. L. M. MONTEIRO, L. B. Produção, teor foliar e qualidade de frutos do pessegueiro "Chimarrita" em função da adubação nitrogenada, na região da Lapa-PR. Rev. Bras. Frutic. 27(2): 295-299, 2005.

9. EMBRAPA. Centro Nacional de pesquisa de solos (Rio de Janeiro, RJ). Sistema Brasileiro de classificação de solos. Brasília: Embrapa Produção de informação; Rio de Janeiro: Embrapa Solos , 1999).

10. ESPÍNDOLA, J.A.A.; GUERRA, J.G.M.;ALMEIDA, D.L. Adubação verde: Estratégia para uma agricultura sustentável. Seropédica: Embrapa-Agrobiologia, 1997. 20p. (Embrapa-CNPAB. Documentos, 42).

11. FAVARETTO, N., A. C. V. MOTTA, C. BARCIK, S. B. LUSTOSA, J. J. COMIN. Biomass and root growth of trifolium vesiculosum affected by boron fertilization in acidic soil of Brazil. In Annual Meeting Soil Science Society of America, Anais. Salt Lake City - Utah, SSSA, 1999. p. 254.

12. GIROLDO, A. de F. Efeito da aplicação de B, Cu e Mn em soja (Glycine max (L.) Merril) cultivada sobre um latossolo de Ponta Grossa, Paraná Soil Science Society of America Proc. 32: 45-48, 1967.

13. GUPTA, U.C. Relationship of Total and Hot-Water Solube Boron, and Fixation of Boron, to Properties of Podzol Soils. Soil Science Society of America Proc. 32: 45-48, 1967. 
ROVEDA, L.F. et al. Qualidade e produtividade em...

14. GUPTA, U. C.; CUTCLIFFE, J.A. Effects of methods of boron application on leaf tissue concentration of boron and control of brown-heart in rutabaga. Can. J. Plant Sci. 58:63-68, 1978.

15. GUPTA, U. C. Boron nutrition of alfafa, red clover, and timothy grown on Podzol soils of eastern Canada. Soil Sci., 137: 16-22, 1984.

16. HABY, V. A.; SMITH, C.R.; PRATT, J.N.; BROWN, J.R. and. SANDERS, J. L. Boron Improves Clover Production. Better Crops With Planta Food, 77(3): 20 - 21, 1993.

17. HANSON, E. How much boron do flowers need? Better crops With Plant Food. 75(4): 10-11, 1991.

18. JONES, JR; J.B. Análisis de los tejidos de las plantas para micronutrientes. In: MORTEVEDT, J.J; GIODANO, P.M; LINDSAY, W. L. (Comp.). Micronutrientes en agricultura. México: AGT Editor, 1983. p. 349-378.

19. LENOBLE, M.E., BLEVINS, D.G. AND MILES, R.J. (1996) Prevention of aluminum toxicity with supplemental boron. II. Stimulation of root growth in an acidic, high-aluminium subsoil. Plant, Cell and Environment 19: 1143-1148.

20. LOMAN Filho, Eltje jan. Fertilização de Boro na cultura do milho associado a nitrogênio e potássio em plantio direto na palha. Brasil. Curitiba: 1999. 2000. 98 f: Dissertação (Mestrado em agronomia)- Setor de Ciências Agrárias, Universidade Federal do Paraná.

21. 9LUCHESE, E. B.; LENZI, E., FAVERO, L.O.B. Levantamento preliminares dos teores de boro nos solos do Paraná- Br. Arq. Biol. Tecnol., Curitiba, 37(2): 345-351, 1994

22. MAHLER, R. L.; HAMMEL, J.E \& HARDER, R.W. The influencie of crop rotation and tillage methods on the distribution of extratable Boron in northern Idaho soils. Soil Science, Baltimore, 139 (1): 67 - 73,1985.

23. MALAVOLTA E.; PIMENTEL-GOMES, F.; ALCARDE, J. C. Adubos e adubações. 2ª edição. São Paulo. Ed Nobel: 1967.

24. MALAVOLTA, E.; VITTI, G. C.;OLIVEIRA, S.A. Avaliação do estado nutricional das plantas. $2^{\mathrm{a}}$ edição. PIRACICABA-SP: Potafos, 1997

25. MARQUES, R.; MOTTA, A.C.V.Análise química do solo par fins de fertilidade. In: Lima. M.R. (org.) et al. Manual de Diagnóstico da Fertilidade e Manejo dos Solos Agrícolas. $2^{\circ}$ Edição ver. E ampl. Curitiba:Departamento de Solos e Engenharia Agrícola, $2003 \mathrm{p} 82-101$.

26. MARSCHNER, H. Mineral nutrition of higher plants. New York: Academic Press, 1986. p. 647

27. MITCHELL, C. C., WINDHAM, S. T., NELSON, D. B., BALTIKAUSKI, M. N. Effect of long-term broiler litter applications on three Coastal Plain soils. Farm Demonstration Report. Auburn University. Auburn, Alabama, 1992.

28. MOTTA, A. C. V.; SERRAT, B. M.; FAVARETTO, N. Fertilidade do solo. In. MONTEIRO, L. B. et al. (ed.) Fruteiras de Caroço: uma visão ecológica, Curitiba, UFPR, 2004, p. 49-57.

29. PAULETTI, V. Disponibilidade e resposta de culturas a micronutrientes no sistema plantio direto. In; Pauletti, V. Seganfredo, R. (ed.). Plantio Direto: Atualização tecnológica, Fundação Cargill/Fund. ABC, São Paulo, 71-96, 1999.

30. PAVAN, M.A. \& CORREA, A.E. Reações de equilíbrio solo-boro. Pesq. Agrop. Bras., Brasília, 23(3):261-269, 1988.

31. PETERSON, J. R.; MACGREGOR, J. M. Boron fertilization of corn in Minnesota. Agron. Journal, 58: 141-142, 1966.

32. PIF-PR-CNPq. 2004. Produção integrada de pêssego para o estado do Paraná, Relatório Técnico enviado ao CNPq, UFPR.

33. PINHEIRO, A. L. Reflexos da Fertilização Mineral de Boro na Estrutura Anatômica, no Crescimento e na seca-de-ponteiro de Eucalyptus citriodora Hook e Eucalyptus camaldulensis Dehnh, no cerrado de Minas gerais, Brasil. Curitiba: UFPR, 1999. (Tese de doutorado)

34. PIZETA L.C.; FERREIRA, M. E.; CRUZ, M. C. P.; BARBOSA, J.C. Resposta do Brócolis, Couve-Flor e Repolho à Adubação com Boro em Solo Arenoso. Horticultura Brasileira. V. 23, n1, p. 51 - 56, 2005.

35. RAIJ, B. VAN., CANTARELLA, H., QUAGGIO, J. A., FURLANI, A. M. C.,ed. Recomendações de adubação e calagem para o estado de São Paulo, 2 ed., Campinas: Instituto Agronômico e Fundação IAC, 1996. 285 p.

36. RUSSEL, D. A. Boron end soil fertility. In: STTEFFERUD, A., ed. The yearbook of agriculture. Washington, the United States department of Agriculture, 1957. pg 121-8.

37. SILVA, F. C.: Manual de Analises Químicas de Solo, Planta e Fertilizante. Brasília, DF,Embrapa Solos, 1999. pg 175-222.

38. SILVA, F. de A. S. e. \& Azevedo, C. A. V. de. Versão do programa computacional Assistat para o sistema operacional Windows. Revista Brasileira de Produtos Agroindustriais, Campina Grande, v.4,n.1, p71-78,2002

39. SMITH, G. R.; HABY, V.A.; GILBERT, C.L. \& PEMBERTON, I.J. Effects of Boron on Seedling Establishment of Annual Legumes. Better Crops With Planta Food, 77 (3): 18 - 19, 1993. 